\title{
ENTRE A MODERNIDADE E A TRADIÇÃO: A INICIAÇÃO SEXUAL DE ADOLESCENTES PIAUIENSES UNIVERSITÁRIASa
}

\author{
Between modernity and tradition: sexual initiation of university teens originally from \\ Piauí \\ Entre la modernidad y la tradición: la inicialización sexual de los adolescentes de las \\ universidades de Piauí
}

Maria Rosilene Cândido Moreira ${ }^{1}$

José Francisco Fernandes Quirino dos Santos ${ }^{2}$

\begin{abstract}
RESUMO
A sexualidade, enquanto fenômeno que propicia momentos singulares de descobrimento de si e do outro, permite a realização de práticas permeadas por simbolizações adquiridas na adolescência. Por sofrer influência de fatores genéticos, sociais e culturais, o comportamento sexual adolescente é, por vezes, permeado por situações conflituosas. 0 presente estudo teve como objetivo desvelar comportamentos sexuais de acadêmicas de Enfermagem da Universidade Federal do Piaú, bem como seus mecanismos de influência, e compreender os aspectos que envolvem a iniciação sexual, considerando os entraves desencadeados pela formação tradicional e aspirações modernizantes. Adotou-se o método etnográfico, aplicando-se entrevistas em profundidade a 12 estudantes, nos meses de outubro e novembro de 2009. As entrevistas relevaram interseção entre comportamento sexual e cultura, permitindo visualizar o poder exercido pelos sistemas de representação social. É importante pontuar sobre a necessidade de mais olhares sobre o assunto por ser emergente nos diversos cenários do existir humano.
\end{abstract}

Palavras-chave: Adolescente. Sexualidade. Comportamento Sexual. Cultura.

\begin{abstract}
Sexuality as a phenomenon that provides unique moments for people discover each other, it means oneself and another, allowing the realization of permeated practices by acquired symbolizations in adolescence. Being influenced by genetic, social and cultural rights factors, adolescent sexual behavior is often permeated by conflict situations. This study aimed to disclose sexual behaviors of Nursing University female students from Federal University of Piauí, as well as their mechanisms of influence and understanding the aspect that surrounds sexual initiation, considering the obstacles caused by the traditional training and modernizing aspirations. We adopted an ethnography method, by applying profound interviews with twelve students in the months of October and November, 2009. Interviews stood out intersection between sexual behavior and culture, allowing you to see the power exercised by the systems of social representation. It is important to emphasize the need for more importance and attention to the subject for being emergent in several scenes of human existence.
\end{abstract}

Keywords: Adolescent. Sexuality. Sexual behavior. Culture.

\section{Resumen}

La sexualidad, como el fenómeno que proporciona momentos singulares de descubrimiento de la propia persona y del otro, permite las prácticas permeadas por símbolos adquiridos en la adolescencia. Por sufrir influencia de factores genéticos, sociales y culturales, el comportamiento sexual adolescente es, muchas veces, permeado por situaciones llenas de conflictos. El presente estudio tuvo como objetivo descubrir comportamientos sexuales de los estudiantes de enfermería de la Universidade Federal do Estado do Piauí, así como sus mecanismos de influencia y comprender los aspectos que envuelven la iniciación sexual, considerando las barreras desencadenadas por la formación tradicional y por las aspiraciones de la modernización. Se adoptó el método etnográfico, aplicándose entrevistas con profundidad a doce estudiantes, en los meses de octubre y noviembre de 2009. Se han revelado cosas en común entre el comportamiento sexual y cultural permitiendo visualizar el poder ejercido por los sistemas de representación social. Es importante poner en punto sobre la necesidad de mirar meticulosamente sobre el asunto, pues son emergentes en los varios escenarios del existir humano.

Palabras clave: Adolescente. Sexualidad. Comportamiento sexual. Cultura.

\footnotetext{
Professora assistente do curso de Graduação em Enfermagem da Universidade Federal do Piauí, Campus Senador Helvídio Nunes de Barros - UFPI/ CSHNB. Mestre em Ciências pelo Programa de Pós-graduação em Saúde Coletiva da Universidade Federal de São Paulo - UNIFESP. Picos - PI. Brasil. E-mail: rosilene@ufpi.edu.br;'Professor visitante do Departamento de Medicina Preventiva da Escola Paulista de Medicina da Universidade Federal de São Paulo - EPM/UNIFESP. Pós-doutor em Epidemiologia Clínica. São Paulo - SP. Brasil. E-mail: jquirino@uol.com.br.
} 


\section{INTRODUÇÃO}

A sexualidade, enquanto fenômeno que permite ao indivíduo experimentar momentos singulares de descobrimento de si e do outro, ao mesmo tempo constitui aspecto ímpar na vivência humana, através da qual se estabelecem padrões de práticas permeadas por simbolizações adquiridas durante a fase da adolescência. ${ }^{1}$

Escolhas relacionadas à sexualidade podem sofrer interferência da família, bem como dos grupos sociais dos quais 0 adolescente passa a fazer parte no cotidiano, 0 que pode resultar em arranjos ideológicos divergentes dos exigidos pelos pais, tornando difícil a adoção de comportamentos sexuais autônomos e independentes.

Vivenciada de maneira diversa entre meninos e meninas, atribui-se à sexualidade feminina o fato de que a mulher tradicionalmente é preparada para o matrimônio e a reprodução, situação que favorece a conformação repressora desta sexualidade, tendo a virgindade e a fidelidade como pontos virtuosos exaltados pelas famílias. Tais considerações influenciam sobremaneira o processo de iniciação sexual das adolescentes, conforme evidenciado em outros estudos desenvolvidos nessa temática. ${ }^{2-3}$

0 ingresso nos grupos sociais, tais como a igreja, os amigos, a universidade, geram diversas mudanças e também oportunidades de repensar determinados conceitos e preferências que no âmbito familiar não poderiam ser criticadas ou mesmo negadas. ${ }^{4} \mathrm{~A}$ adolescente começa a ressignificar pontos que anteriormente eram inquestionáveis, culturalmente instituídos e seguidos por imposição dos parentes.

Com efeito, inúmeras podem ser as consequências advindas das situações conflituosas resultantes do que é formalmente ensinado pelos pais e daquilo que as jovens vislumbram após a descoberta do mundo acadêmico. Pode-se aqui mencionar o baixo rendimento escolar, dificuldades de relacionamento entre pares, estados de depressão e comportamentos contrários aos ensinados, atrelados ao problema da não autonomia sexual.

Compreender como se forma o pensamento da adolescente que iniciou ou que pretende iniciar a vida sexual, bem como seus aspectos influentes, recai sobre o conhecimento das relações de poder estabelecidas neste campo. A formação familiar tradicional, a influência dos dogmas religiosos, os desejos e sonhos modernizantes adquiridos a partir do convívio com outras garotas provenientes de outros segmentos sociais podem resultar em conflitos entre o pensar, o desejar e o fazer da adolescente no tocante às práticas sexuais.

As relações de poder exercem intensa contribuição na formação do pensamento e comportamento sexual da adolescente, posto que há uma troca de influências entre a garota e seu meio social, ocorrendo momentos em que há predomínio de um sobre o outro, podendo desencadear uma confusão de papéis a serem assumidos pela adolescente neste processo de definição da vida adulta. ${ }^{5}$

Convém analisar o fato de que muitas garotas provem de cidades interioranas, deslocadas de suas famílias para morarem em cidades maiores e darem seguimento ao processo de formação educacional e profissional, a exemplo, a formação superior. Isso pode desencadear um processo de intensa mudança de significados, padrões e comportamentos dantes recheados de dispositivos de teor proibitivo pelos próprios pais ou pela religiosidade.

Há ainda que ressaltar os conflitos resultantes da coexistência de valores modernos e tradicionais que envolvem a iniciação sexual das adolescentes. Os valores atribuídos à virgindade podem vir acompanhados de sentimentos ambíguos que ora apontam para sua preservação como forma de exaltar a reputação da garota, e assim manter a tradição, ou à sua perda, como manifestação da intensidade do amor dispensado ao parceiro, atitude que agrega valores modernos ao sexo. ${ }^{6}$

Assim, podem emergir do ingresso no segmento universitário alguns conflitos, uma vez que a adolescente a partir desse momento descobrirá outros padrões a serem comparados aos seus, advindos de outras formaç̧ões familiares, sob a orientação de outros dogmas religiosos, além de conviver com pessoas de extratos sociais diversos, com costumes próprios, muitos deles, mais modernizantes do que os seus.

Tais mudanças levam a crer que o comportamento sexual da adolescente universitária seja decorrente das relações que se estabelecem a partir do momento em que a garota percebe essa nova condição. Daí a importância de se esmerar no aprofundamento dos fatores que determinam a iniciação sexual, bem como suas práticas, os pressupostos que envolvem 0 pensamento e o compor tamento das adolescentes no tocante as preferências sexuais.

0 presente estudo teve como objetivo desvelar os sentimentos manifestos por adolescentes piauienses universitárias no tocante ao processo de iniciação sexual, considerando os diversos mecanismos de influência existentes, a fim de compreender como se estruturam os significados elaborados por elas quanto aos aspectos que envolvem a sexualidade humana, levando em conta a formação tradicional e aspirações modernizantes, manifestados através das atitudes relatadas por elas diante dos enfrentamentos próprios do existir humano.

\section{METODOLOGIA}

0 presente estudo foi do tipo etnográfico, pois esse tipo de pesquisa tem como meta a compreensão do mundo simbólico vivido pelas pessoas, a partir dos seus olhares e dos sentidos atribuídos por elas aos fenômenos experimentados, ${ }^{7}$ aplicandose nesta investigação, aos aspectos relacionados a iniciação sexual compreendida e vivida pelas adolescentes universitárias. Através deste tipo de investigação é possível captar questões muito particulares, tais como significados, comportamentos e 
valores atribuídos, adentrando assim no campo dos fenômenos sociais.

Vale ressaltar que o trabalho do etnógrafo não está restrito a aplicar o método na atividade de campo; além disso, a ele cabe, essencialmente, a interpretação dos dados colhidos, possibilitando o desvelar dos significados agregados. ${ }^{8}$

Compuseram o universo da pesquisa 129 adolescentes que haviam ingressado no curso de Enfermagem da Universidade Federal do Piauí/Campus Senador Helvídio Nunes de Barros, na cidade de Picos/PI, aprovadas no processo seletivo vestibular dos anos de 2007 e 2008, sendo entrevistadas 12 delas por atenderem aos seguintes critérios de inclusão: estar cursando o segundo semestre de enfermagem no ano de 2009; possuir idade entre 18 e 19 anos; aceitar o convite para participar da pesquisa e comparecer ao local indicado para a realização da entrevista.

Optou-se por entrevistar adolescentes do gênero feminino por ser mais acessível à pesquisadora tratar do tema com este público. A opção por alunas do segundo semestre de enfermagem deveu-se ao fato de esse grupo receber aulas da pesquisadora, um atributo que facilitou consideravelmente a sua aceitação para participarem da pesquisa. A escolha da faixa etária deveu-se ao fato de esta ser considerada maioridade civil, o que dispensa autorização prévia dos pais, evitando um possível constrangimento da adolescente em falar sobre o tema, sob alegação de que seus genitores teriam conhecimento do intuito da pesquisa. Utilizou-se como local para realização das entrevistas um laboratório de pesquisa do Campus, por ser um ambiente reservado, evitando que as conversas fossem ouvidas ou interrompidas.

Após aprovação do projeto pelo Comitê de Ética em Pesquisa da Universidade Federal de São Paulo - UNIFESP (Protocolo no.20090114220825 e Parecer no.0083/09 em 27/03/2009) iniciaram-se as entrevistas, momentos em que foram esclarecidos os objetivos da pesquisa e a garantia do sigilo absoluto sobre as informações colhidas. 0 termo de consentimento livre e esclarecido (TCLE) foi lido e assinado, seguindo-se do pedido para usar o gravador de voz. Cada entrevista teve duração média de trinta minutos, ocorrendo nos meses de outubro e novembro de 2009.

Os depoimentos captados foram transcritos, lidos e codificados, com base na técnica de Análise de Discurso. ${ }^{9}$ Emergiram oito categorias temáticas que possibilitaram conhecer um pouco do universo-vida das adolescentes, estando apresentadas neste artigo três delas: significados de sexualidade, dúvidas sobre a iniciação sexual, influência do parceiro na decisão pela iniciação sexual.

\section{RESULTADOS E DISCUSSÃO}

Todas as participantes do estudo são provenientes de cidades interioranas do estado do Piauí. Algumas já vivenciaram a experiência de morar longe dos pais, pois em algumas destas cidades não há ensino médio, fazendo-se necessário ir para a capital (Teresina) ou cidades de maior porte, a fim de complementarem os estudos.

É valioso ressaltar que todas as entrevistadas moram na cidade de Picos, algumas com os pais, outras com irmãos, e há ainda outras que moram com amigos provenientes de suas cidades de origem, ou que conheceram após o ingresso na universidade. Esse arranjo de moradias decorre do fato de a universidade ainda não dispor de uma residência estudantil, e também pelo alto valor cobrado nos imóveis locais, fazendo com que as pessoas se associem na divisão das despesas imobiliárias. Assim, tem-se que 6 adolescentes (50\%) moram com os pais e $5(41,7 \%)$, com amigos. Uma adolescente $(8,3 \%)$ informou morar sozinha.

No tocante ao relacionamento afetivo, 8 garotas $(66,7 \%)$ informaram ter namorado, enquanto $4(33,3 \%)$ não estavam se relacionando no período da coleta de dados.

Ainda sobre o namoro, observou-se que as adolescentes do estudo que tinham namorado haviam iniciado o relacionamento a pelo menos dois anos, com tempo de duração variando entre um e seis anos. Os respectivos namorados são os primeiros parceiros sexuais das garotas não virgens. Para as garotas que ainda não iniciaram a atividade sexual, o namorado atual é o primeiro relacionamento afetivo delas.

Com relação à iniciação sexual, apenas 3 adolescentes (25\%) responderam positivamente, enquanto as demais (75\%) informaram o contrário.

\section{Atribuindo significados à sexualidade}

0 termo sexualidade surgiu no final do século XIX, conferindo maior amplitude ao tema e com limites morais menos precisos, significando algo além de uma mera união com fins reprodutivos, vinculando-se a sensações de desejo e fantasias, carregadas de representação simbólica. ${ }^{10} \mathrm{~A}$ partir desse simbolismo, o que antes era silenciado, agora, com a linguagem simbólica passa a ser ensinado, regulamentado, reprimido ou supervalorizado, sob condicionantes sociais possuindo estreita relação com as experiências emocionais de cada indivíduo.

É condição essencial que as adolescentes compreendam a sexualidade para que possam desfrutar das consequências que ela proporciona para suas vidas. Daí a importância em se conhecer o que pensam essas jovens sobre a temática.

Quando inqueridas sobre como concebem o tema sexualidade, algumas depoentes o relacionaram a aspectos de maior amplitude do que apenas ao ato sexual; porém, em algumas respostas emergiu o padrão tradicional, que atribui à sexualidade a mera realização de prática do sexo, revelando a influência cultural conversadora nestas jovens, conforme pode ser percebido nas falas a seguir:

É ser feminino, sobre o modo de vestir, além das relações sexuais, a feminilidade... a vaidade... (E1) 
Eu acho que, por eu ser evangélica, acho que o sexo foi feito para o casamento, só deve acontecer após o casamento e também porque a minha família é muito tradicional... (E2)

Eu vejo como a relação que existe entre um homem e uma mulher, seja ela qual for, mas no relacionamento tem que haver as diferenças entre homem e mulher nas questões da sexualidade, mas pesa mais pro lado sexual. (E3)

Acho que quando eu manifesto minha forma de pensar, nas minhas atitudes, eu acho que estar mostrando um pouco da minha sexualidade... (E8)

Nota-se, em alguns discursos, uma convergência conceitual no que diz respeito a sexo e sexualidade, embora esses termos obtenham conceitos diferentes por alguns autores, sendo o primeiro o conjunto de características fisiológicas que diferem machos e fêmeas, enquanto sexualidade é a vida sexual do indivíduo. ${ }^{11}$ Tal convergência parece refletir os modos repressores utilizados pela família, religião e sociedade sobre as mentes humanas, no intuito de negar sua natureza humana.

Observa-se também em alguns depoimentos que houve uma associação dos termos sexo e sexualidade, em que 0 primeiro é componente do segundo, denotando uma maneira modernizante de pensar das adolescentes estudadas, traduzindo-se no real significado atribuído por elas, fato confirmado também em outro estudo da área. ${ }^{12}$

A Sociedade Brasileira de Pediatria (SBP) e a Federação Brasileira das Sociedades de Ginecologia e Obstetrícia (FEBRASGO) ${ }^{13}$ consideram desafiador o processo de educação sexual do adolescente, sendo talvez a causa das dificuldades apresentadas pelas entrevistadas em atribuírem significados à sexualidade. Para essas entidades, a família, a escola, os profissionais de saúde e a sociedade em geral devem ser parceiros no processo educativo do adolescente, pois preconizam que tal educação é um direito de todo adolescente brasileiro.

Apenas uma respondente reconheceu que sente dificuldade em conceituar o tema, considerando isso uma limitação pessoal:

\section{É difícil responder, porque eu sou tão fechada pra essa área...(E9)}

0 depoimento desta adolescente retrata a maneira como muitas adolescentes provenientes de cidades interioranas, onde os costumes são essencialmente conservadores, chegam à cidade grande, onde passarão a viver para realizarem os estudos superiores, convivendo com outras adolescentes tipicamente urbanas, com concepções e práticas distintas das suas, por vezes extremamente contrárias, revelando a intrínseca influência cultural.

A pouca experiência de vida, o desconhecimento de situações típicas da cidade grande, tais como os espaços de lazer, as festas estilizadas, o ambiente universitário, um maior grau de independência dos pais, a liberdade dos adolescentes em frequentarem os lugares típicos urbanos (bares, restaurantes, bailes, academias de ginástica, clubes recreativos) dentre outros fatores, podem fazer com que a adolescente sinta dificuldade em se adaptar a esse novo locus que não é somente geográfico, mas também, social.

Emergem, estimulados por esse novo ambiente, conflitos de ordem intelectual, moral, social, que fazem com que a adolescente analise sua forma de pensar, seus valores antes considerados imutáveis, acarretando a formulação de novos conceitos, de, que a partir desse momento, será exigida dessa adolescente uma postura cada vez mais autônoma em relação a si e aos outros.

No ambiente universitário, os relacionamentos ocorrem entre adolescentes provenientes de diversas cidades, cada uma trazendo consigo os ensinamentos familiares e os padrões morais de suas procedências, proporcionando uma mistura de significados, tabus e crenças relacionadas a sexualidade. Deste modo, arranjam-se os novos modelos do que seja sexualidade, dos comportamentos e das atitudes tomadas em relação ao sexo, das preferências manifestadas entre os pares, enfim, um processo de adaptação que pode durar dias ou meses, dependendo das questões familiares, morais, religiosas que determinaram o modo de significar elaborado por cada adolescente..$^{14}$

\section{Dúvidas quanto à iniciação sexual}

Considerando que a iniciação sexual ocorre de maneira única para cada pessoa, que difere entre homens e mulheres e que sofre diversas influências, resolveu-se explorar os determinantes para o início da atividade sexual das adolescentes do estudo.

Inicialmente, procurou-se averiguar se as entrevistadas já haviam iniciado seus intercursos sexuais. Em seguida, de posse dessa informação, passou-se a questionar acerca dos fatores contribuintes ou impeditivos para a decisão pelo início ou não da atividade sexual.

A maioria das entrevistadas afirmou não ter iniciado a prática sexual, e, ao serem inqueridas sobre os fatores impeditivos para esse início, diversos foram os motivos apresentados pelas jovens, demonstrando haver um leque de situações pessoais, familiares, morais, religiosas e sociais que funcionam como empecilho no processo de iniciação sexual:

Não, logo eu tenho consciência que pra mim, o certo, é só depois do casamento, então eu não vou fazer uma coisa que possa me prejudicar... (E2) 
Não... por causa do medo de mãe e pai, da reação deles; pai disse que, se sonhar, me bota pra fora de casa... (E4)

Não sei, é um bloqueio... eu uso muito a razão, eu não consigo deixar ficar naturalmente, eu não consigo... eu acho que é medo... da reação da minha mãe... e eu também tenho medo de fazer e o namoro não dar certo... (E9)

Não, porque eu acho que... por causa da minha família, dos costumes... eu acho que não coube ainda... (E11)

Assim, eu comecei a namorar cedo, mas eram só ficantes, assim, porque eu sempre fui muito criada quieta, pelo fato de eu ser evangélica, desde os 9 anos que eu sou evangélica...mas aí, nunca despertei pra isso, eu nunca fui em festa, balada, não conheço, nunca fui... (E12)

São notáveis nos discursos as influências familiares e religiosas que marcam definitivamente a opção de algumas depoentes por não iniciarem a prática sexual. As proibições impostas pela religião, tais como o casamento como requisito para haver a iniciação sexual e a privação em frequentar festas, refletem uma obediência rígida, sem qualquer expressão crítica por parte das adolescentes, que são algumas vezes enfáticas ao afirmarem a obrigatoriedade de seguir os preceitos religiosos.

0 medo de estarem realizando algo errado, da censura e do castigo dos pais são pontos que assinalam o arcabouço conservador da educação familiar presente na vida das adolescentes, cujos valores de aprovação ou reprovação auxiliam a definir quando e de que maneira se dará o processo de iniciação sexual das mesmas. Ao mencionar que o pai afirmou expulsá-la de casa se "sonhasse" que ela havia iniciado a vida sexual, a adolescente denuncia o quanto é complexo vivenciar o desejo sexual emergente, tendo como ponto de partida a rejeição/ proibição dos pais, em uma perspectiva conservadora, muitas vezes imbricada por uma intensa mistura de mitos e preconceitos provenientes de gerações anteriores,$^{15}$ influenciando na abdicação do desejo sexual.

Alguns autores ${ }^{16}$ apontam que os fatores culturais, a vergonha e o preconceito fazem com que muitos pais tenham dificuldade em dialogar sobre sexualidade com seus filhos e, especialmente, a filha. 0 incômodo vivenciado por eles quando se deparam com a necessidade deste tipo de diálogo pode ocorrer também pelo sentimento de impureza que agregam ao tema ou por desconsiderarem sua importância. ${ }^{17}$

De um modo ou de outro, a família mostra-se passiva diante da abordagem da sexualidade dos filhos, delegando este papel educativo a outros grupos sociais, como a escola e os amigos, mantendo este silêncio de geração em geração, ${ }^{16}$ propiciando maior aproximação do adolescente a outros jovens e afastando-o dos familiares.

Mesmo tecendo motivos que as impossibilitam ter atividade sexual, as entrevistadas expressaram sentir desejo sexual, conforme observa-se nos depoimentos:

Acho que todo mundo tem desejo, mas eu não tenho vontade de descobrir não. (E2)

O pior, é que os dois mostram da mesma forma que querem, mas quando sabe que está mais perto, aí eu corto, eu não quero. (E3)

...eu conversava com ele mas eu nunca deixava claro que eu queria, até no último momento eu lembro dele ter perguntado se era isso mesmo que eu queria... (E8)

... de saber como é, o que acontece, quais são as sensações, os sentimentos, como é, se é bom, porque tem gente que fala que é bom, tem gente que fala que é ruim...(E12)

Nos depoimentos, observa-se que as adolescentes têm consciência de que há desejo sexual, algumas vezes manifestado também pelo parceiro. Porém, o que é bastante curioso é como elas lidam com esse desejo. A maioria das participantes do estudo resiste, evitando pensar ou conversar sobre o assunto; uma delas até reconhece que sente desejo, mas que não tem vontade de descobrir nada sobre a prática do sexo.

Um estudo sobre os padrões de sexualidade humana ${ }^{10}$ destaca que o comportamento humano é resultante de algo além das regras morais, denominado desejo sexual, considerando que este desejo constitui uma necessidade humana básica. Nesse enfoque, as regras morais é que possuem o dom de caracterizar e de transformar a intensidade do desejo sexual das pessoas, e não de anulá-lo, uma vez que é um caractere aprendido e repassado entre as pessoas, portanto, também sofre influências das regras de moralidade impostas e internalizadas.

Durante muito tempo, o desejo sexual esteve vinculado à noção de instinto, cujo intuito, em todas as espécies, era sua manutenção, sendo disparado pelos hormônios existentes nos machos e fêmeas, especialmente, nas fêmeas, através do cheiro exalado que atraía os machos durante a fase fértil. Para os humanos, porém, existia uma diferenciação que fazia com que tanto machos quanto fêmeas escolhessem seus pares para a cópula, utilizando de outros artifícios que não somente os hormonais para a seleção e escolha do outro, tais como os atributos psicológicos e sociais. Dessa maneira, surge o termo sexualidade para estudar o comportamento e as atitudes 
dos humanos, abolindo a concepção de instinto, substituindo-o por desejo sexual. ${ }^{10}$

Portanto, ter desejo sexual não significa ter impulso sexual, nem tampouco praticá-lo. Os impulsos que levam uma pessoa a ter atividade sexual são, da mesma forma que o desejo, multifacetados. Envolvem o sexo, carência afetiva, necessidade de atenção, de carinho, exercício de poder, dentre outros, cada vez mais afastando-se da meta reprodutiva, porém, não anulando-a. ${ }^{10}$

A dúvida se devem iniciar a vida sexual citada por algumas garotas demonstra o quanto é difícil para elas tomarem esta decisão, pois o desejo é crescente, de difícil controle, acarretando, conforme citado por uma delas, dúvida até pelo parceiro se a mesma já havia se decidido.

Apenas uma adolescente relatou nunca ter tido desejo sexual:

Assim, de praticar nunca tive vontade... porque a partir do momento em que a gente passa a pensar a gente passa a ter vontade... (E6)

Entendendo que há uma confusão entre o entendimento de desejo e impulso por parte da entrevistada, percebe-se em seu depoimento que a mesma possui desejo sexual, porém, por pertencer a uma religião que proíbe tal prática, nega a manifestação desta necessidade humana e evita ter contato com o que pode desencadear o impulso sexual.

\section{0 namorado e a iniciação sexual: "forçando a barra" ou à espera da decisão?}

Considera-se o namoro uma importante etapa no desenvolvimento do ser humano, pois se trata de um relacionamento social afetivo-sexual. Quando uma adolescente começa a namorar, diz o mesmo autor, ela geralmente modifica o seu comportamento com relação a sua família, colocando-a em segundo plano, e deixando o namoro como sua principal atividade. Em virtude de tal acontecimento, é natural que ocorram algumas alterações na dinâmica familiar, que podem ser positivas ou negativas.

É no namoro que o adolescente escolhe seus programas e suas conversas, e por mais que tentem controlá-lo isso é impossível, pois não há como impossibilitá-lo de ter conversas íntimas ou sexuais. Porém, o padrão moral vigente condena esse tipo de prática. A sociedade ainda hoje espera que as garotas consigam eximir-se dos desejos sexuais, escondendoos, fingindo não os possuírem, negando os insistentes convites do parceiro para o intercurso sexual, que é também uma forma de manifestação do desejo masculino. ${ }^{10}$

No presente estudo, todas as garotas que afirmaram terem iniciado suas práticas sexuais encontravam-se namorando, especificamente, com o mesmo parceiro com quem haviam tido a primeira relação sexual. Além disso, a duração do namoro oscilou entre oito meses e um ano, e a diferença entre o início do namoro e a primeira relação sexual variou entre quatro e seis meses, sugerindo que há, de maneira geral, uma fase "pré-prática sexual" no namoro.

Um estudo ${ }^{4}$ com adolescentes residentes na zona leste do município de São Paulo revelou que as garotas que estavam namorando na época da pesquisa tiveram 5,6 vezes a chance de iniciar a vida sexual do que aquelas que não estavam namorando, confirmando a influência do namoro no processo de decisão pela iniciação sexual feminina, independente de outros fatores.

Com base nesse pressuposto, perguntou-se às adolescentes se elas recebiam convites do namorado para iniciarem a prática sexual. Eis algumas respostas:

Não... porque ele tem o mesmo conceito, porque a gente é da mesma religião. (E2)

Ô, com certeza, 4 anos, Ave Maria, só o que surge... mas pela minha cabeça não vai não... pela minha criação, de ser criada assim de imaginar que deve ser só depois do casamento e éo que eu quero, eu penso na minha religião também, que diz que eu tenho que casar virgem, e que eu me considero fiel a ela e que eu não quero decepcionar meus pais... (E3)

Eu conversava com ele direitinho, que não, que eu sou a favor da virgindade até o casamento... só que era assim, entrava num ouvido e saía no outro... (E4)

Sim, mas eu sabia contornar a situação... ele queria, ele insistia bastante, mas eu dizia pra ele que não era assim... Aí tinha que segurar... às vezes, ele dizia que eu era fria, mas não era bem assim. (E7)

Percebe-se através das falas que a virgindade ainda é posta como quesito importante para as adolescentes, sendo 0 ponto central na decisão sobre o início ou não do intercurso sexual com o parceiro. Sobre este aspecto, estudiosos ${ }^{18}$ enfatizam que praticamente todas as culturas possuem mecanismos de imposição de normas proibitivas à atividade sexual. Os rituais de iniciação sexual são estabelecidos sob o ponto de vista moral e cabe aos adolescentes conviverem com essa normalização.

Assim, a proibição histórica, cultural, familiar e religiosa imposta para a mulher ao longo dos séculos, emerge nos discursos da atualidade ainda de maneira enfática, aparecendo nos depoimentos quando elas atribuem a responsabilidade pela não iniciação sexual aos pais ou à religião.

Também é possível perceber como a tradição impera sobre a modernidade, fazendo com que a adolescente experimente sensações ambíguas entre desejo e medo, 
moderno e tradicional, ${ }^{14}$ situações que se cruzam no cotidiano das entrevistadas, nas situações mencionadas por elas. 0 universo vivido pelas jovens no contexto atual, no qual há liberdade para viver as experiências sexuais, esbarra nos freios emitidos pelas conformações moralistas e religiosas para não praticá-las. Nesse emaranhado de censuras e punições, o medo de experimentar o sexo à revelia das influências conservadoras vai se dissipando e a iniciação sendo adiada, sobrepondo o valor tradicional ao moderno, fazendo com que a adolescente encontre outras maneiras de satisfazer o desejo sexual, seu e do parceiro, ou justificar a não realização.

Observou-se também que as adolescentes, quando perguntadas se a decisão de não iniciar a prática sexual era compreendida pelo namorado, responderam afirmativamente, demonstrando haver conversas sobre o comportamento sexual entre os dois, porém, voltadas para a abstinência, pois mencionaram que ao parceiro caberia conformar-se com a decisão e esperar até que algo acarretasse uma mudança na situação (pensamento ou vontade). Tal fato pode ser observado nas respostas a seguir:

Entende. Ele sabe que quando acontece alguma coisa ... quando eu digo que não dá mais pra ir para frente... às vezes, ele fica assim meio chateado, $e$ fica achando que eu é que não quero, mas depois ele entende. (E3)

Édificil [risos]... mas ele entende, ele sabe que por causa da família, ele sabe que hoje o sonho ainda de muitas mulheres é casar virgem, e ele diz que entende. (E4)

...eu tive uma conversa com ele e ele me disse que em momento algum iria forçar nada, que por ele esperava o tempo que fosse preciso, que não iria colocar nenhum tipo de pressão... (E8)

Ele fala que espera, que entende, mas se for namorar muito tempo... não vai esperar a vida inteira até casar...(E9)

Por enquanto ele aceita, nunca me cobrou isso não. (E12)

Assim foi possível verificar, em alguns discursos e na expressão de sorriso de uma adolescente, que o impulso sexual é satisfeito, ou pelo menos amenizado, através das carícias corporais, evitando-se somente a penetração sexual. A chateação do namorado, o pensamento de que a menina não quer ter relação, dentre outros sentimentos relatados pelas entrevistadas, denota o quão é difícil também para o parceiro controlar o desejo sexual e compreender a opinião da garota.
Apenas uma adolescente informou não conversar sobre sexo com o namorado, fato endossado pelo depoimento que atribui aos fatores religiosos tal proibição:

Nós conversamos sobre várias coisas, mas sobre isso não... (E6)

Para uma adolescente que informou que seu parceiro também não havia iniciado a vida sexual, foi perguntado qual seria sua reação se ele comunicasse que havia buscado outra pessoa para realizar seu primeiro intercurso. Imediata e enfática foi a resposta da adolescente:

Dentro do relacionamento? Eu terminaria, porque isso era sinal de que ele não me amava não, se ele deixou isso aí passar na frente... porque se ele quer, eu também quero, e eu não sou obrigada a procurar outra pessoa... (E3)

Nessa fala identifica-se o ideal de fidelidade mútua, sentimento bastante presente nos discursos religiosos, quer sejam católicos quer sejam evangélicos, historicamente perpetuado, em que um deve esperar sexualmente pelo outro, resultando invariavelmente no casamento entre os dois.

Um fato curioso percebido foi que, enquanto algumas garotas consideraram a prática sexual uma "prova de amor", outras manifestaram que tal prática, quando realizada fora do namoro, significaria "sinal de não-amor", mesmo quando o namorado insistia para realizá-la com a garota. Há, portanto, uma ambivalência de significados quando a referência é a relação sexual no namoro.

Assim, necessário se faz que outras investigações sejam realizadas no tocante às práticas de namoro entre adolescentes, para que seja melhor compreendido esse complexo e multifacetado processo relacional-afetivo.

\section{CONSIDERACÕES FINAIS}

As adolescentes entrevistadas revelaram diversos pontos de interseção entre o campo da sexualidade e a cultura, permitindo visualizar ainda em seus enunciados discursivos o poder exercido pelos sistemas de representação social.

Significados de sexualidade foram descritos pelas entrevistadas de maneira bastante complexa, revelando pontos ambíguos, ora dirigindo-se para o biológico, o genital, ora aproximando-se da afetividade, do desejo manifesto, do ser-pessoa, na confusão com sexo, ato sexual e desejo sexual, denotando certo desconhecimento sobre a complexidade que envolve a temática, ao tempo em que sugere haver uma estreita ligação simbólica do tema ao desejo sexual.

Medo e desejo estiveram fortemente associados nos depoimentos das entrevistadas, que exprimiram o sofrimento gerado pelo conflito entre o pensar e o (não)fazer, no tocante ao compor tamento sexual. As adolescentes reconhecem 
nelas mesmas o desejo sexual, embora muitas ainda relutem e resistam a ele.

0 namorado foi desenhado pelas entrevistadas como alguém também possuidor de desejo sexual, embora tendo que ceder à resistência da garota, na decisão pela não prática sexual. Como um traço marcante desse grupo, observou-se que os relacionamentos afetivos são estáveis e duradouros, contribuindo, talvez, para a adoção de um posicionamento de opinião predeterminada acerca da sua própria sexualidade.

Compreender como se estruturam os comportamentos sexuais das adolescentes pode servir como parâmetro para o desenvolvimento de abordagens especíificas no âmbito das instituições de educação superior, com programas que visem oferecer apoio psicoeducacional individualizado, desvencilhado de preconceitos os quais até bem pouco tempo limitavam suas ações à prevenção da gravidez precoce e das doenças sexualmente transmissíveis. A Universidade enquanto instituição formadora tem importante contribuição a dar na educação sexual dos jovens universitários, pois a escola significa 0 segundo maior grupo social que 0 adolescente frequenta $\mathrm{e}$ nele deposita confiança.

Destaca-se também a necessidade de abordagem da sexualidade no ambiente universitário pelos docentes, especialmente os professores dos cursos de Enfermagem, pois é preocupante o fato de essas jovens viverem de maneira conflituosa a sua sexualidade, sendo futuras multiplicadoras e influenciadoras da opinião e necessitando estar bem informadas e livres de preconceitos, pois serão formadas para realizarem 0 cuidado das pessoas com idades e necessidades de saúde diversas, inclusive nos aspectos que envolvem a sexualidade da clientela que será por elas assistida.

\section{REFERÊNCIAS}

1. Ressel LB, Gualda DMR. A sexualidade como uma construção cultural: reflexões sobre preconceitos e mitos inerentes a um grupo de mulheres rurais. Rev Esc Enferm USP. [on-line] 2003 set; [citado 2010 jan 07]; 37(3): [aprox. 6 telas]. Disponível em: http:// www.scielo.br.

2. Altmann H. Educação sexual e primeira relação sexual: entre expectativas e prescrições. Estud Fem. [on-line] 2007 maio/ago; [citado 2011 jan 13]; 15(2): [aprox. 23 telas]. Disponível em http:/ /www.scielo.br.

3. Amaral MA, Fonseca RGMS. Entre o desejo e o medo: as representações sociais das adolescentes acerca da iniciação sexual. Rev Esc Enferm USP. [on-line] 2006 out/dez [citado 2011 jan 13]; 40(4): [aprox. 8 telas]. Disponível em http://www.scielo.br.
4. Borges ALV, Latorre MRDO, Schor N. Fatores associados ao início da vida sexual de adolescentes matriculados em uma unidade de saúde da família da zona leste do Município de São Paulo, Brasil. Cad Saude Publica. [on-line] 2007 jul; [citado 2010 fev 20]; 23(7): [aprox. 11 telas]. Disponível em: http://www.scielo.br.

5. Fonseca AD, Gomes VLO, Teixeira KC. Percepção de adolescentes sobre uma ação educativa em orientação sexual realizada por acadêmicos(as) de enfermagem. Esc Anna Nery [on-line] 2010 jun; [citado 2010 jul 02]; 14(2) [aprox. 7 telas]. Disponível em: http://www.scielo.br.

6. Borges ALV. Relações de gênero e iniciação sexual de mulheres adolescentes. Rev Esc Enferm USP. [on-line] 2007 out/dez; [citado 2011 jan 13]; 41(4): [aprox. 8 telas]. Disponível em http:// www.scielo.br.

7. Pope C, Mays N. Pesquisa qualitativa na atenção à saúde. $2^{\mathrm{a}}$ ed. Porto Alegre: Artmed; 2005.

8. Nakamura E. 0 lugar do método etnográfico em pesquisas sobre saúde, doença e cuidado. In: Nakamura E, Martin D, Santos JFFQ, organizadores. Antropologia para enfermagem. São Paulo: Manole, 2009; p. 15-35.

9. Gill R. Análise de discurso. In: Bauer MW, Gaskell G. Pesquisa qualitativa com texto, imagem e som: uma manual prático. $2^{\mathrm{a}}$ ed. Petrópolis(RJ): Vozes; 2003. p.244-70.

10. Andrade-Silva MC. Olhares sobre o desejo sexual. Rev Bras Sex Hum [on-line] 2007 jan/jun; [citado 2009 mai 10]; 18(1): [aprox.18 telas]. Disponível em: www.sbrash.org.br.

11. Ximenes S. Minidicionário da língua portuguesa. São Paulo: Ediouro; 2001.

12. Oliveira DC, Gomes AMT, Pontes APM, Salgado LPP. Atitudes, sentimentos e imagens na representação social da sexualidade entre adolescentes. Esc Anna Nery. [on-line] 2009 dez; [citado 2010 jul 07] ; 13(4): [aprox. 7 telas]. Disponível em: http://www.scielo.br.

13. Sociedade Brasileira de Pediatria-SBP. Federação Brasileira das Sociedades de Ginecologia e Obstetrícia-FEBRASGO. Contracepção e ética: diretrizes atuais durante a adolescência. Rev Adolescência \& Saúde [periódico on-line]. 2005 jun; [citado 2009 mai 27]; 2(2): [aprox. 2 telas]. Disponível em: http:// www.adolescenciaesaude.com.

14. Rangel DLO, Queiroz ABA. A representação social das adolescentes sobre a gravidez nesta etapa de vida. Esc Anna Nery. [on-line] 2008 dez; [citado 2010 jun 28]; 12(4): [aprox. 9 telas]. Disponível em: http://www.scielo.br.

15. Sousa LB, Fernandes JFP, Barroso MGT. Sexualidade na adolescência: análise da influência de fatores culturais presentes no contexto familiar. Acta Paul Enferm. [on-line] 2006 out/dez; [citado 2011 jan 18]; 19(4): [aprox. 5 telas]. Disponível em: http:// www.scielo.br. 
16. Monteiro CSF, Costa NSS, Nascimento PSV, Aguiar YA. A violência intra-familiar contra adolescentes grávidas. Rev Bras Enferm. [online] 2007 jul/ago [citado 2011 jan 15]; 60(4): [aprox. 3 telas]. Disponível em: http://www.scielo.br.

17. Alves AS, Lopes MHBM. Uso de métodos anticoncepcionais entre adolescentes universitários. Rev Bras Enferm. [on-line] 2008 mar/abr [citado 2011 jan 15]; 61(2): [aprox. 7 telas]. Disponível em: http:// www.scielo.br.

18. TaquetteSR, Vilhena MM. Uma contribuição ao entendimento da iniciação sexual feminina na adolescência. Psicol Estud. [on-line] 2008 jan/mar; [citado 2011 jan 18]; 13(1): [aprox. 10 telas]. Disponível em: http:// www.scielo.br.

\section{NOTA}

¿Este artigo é parte da dissertação de mestrado intitulada "Aspectos do comportamento sexual nos discursos de adolescentes piauienses universitárias", apresentada ao Programa de Pós-graduação em Saúde Coletiva da Universidade Federal de São Paulo (UNIFESP). 